openUP

\title{
SUPPORTING AN INFLATION TARGETING POLICY WITH THE MEASUREMENT OF INFLATION CREDIBILITY
}

\author{
JANNIE ROSSOUW AND FANIE JOUBERT
}

\begin{abstract}
Inflation targeting anchors inflation expectations, which are not within the sphere of control of the authorities, but can only be influenced over time by consistent policy. As public distrust of inflation figures will feed through to inflation expectations, this paper highlights pilot studies measuring the credibility of inflation in terms of an inflation credibility barometer. Despite initial discouraging results, the conclusion is that knowledge and information improve the credibility of inflation, but only one inflation rate (ideally the one used for inflation targeting purposes) should be communicated. Moreover, the rate used for targeting purposes should be specified with ease of communication in mind.
\end{abstract}

INFLATION TARGETING as a monetary policy framework was introduced for the first time in 1990 by New Zealand. By adopting this framework, New Zealand introduced a monetary policy approach which clearly stated its ultimate objective: price stability. Inflation targeting was preceded in many countries by a policy of money supply growth targets. Owing to international financial integration, countries increasingly found that money supply growth targets no longer produced the desired results as an anchor for monetary policy. The scene was therefore set for a new approach to monetary policy, in the same way as direct credit controls had been replaced as a monetary policy framework by money supply growth targets in the 1970s and 1980s. At the time when South Africa adopted an explicit inflation target in February 2000, it became "... the $15^{\text {th }}$ country to formally adopt this framework" (Mohr et ai, 2004:374).

As inflation targeting is a forward-looking policy, central banks using such an approach have generally adopted three important support measures for their policy frameworks, as is explained in section one of this paper. Section two highlights the preference for an explicit monetary policy objective such as an inflation target over monetary policy discretion. Section three highlights the current measures employed to support a policy of inflation targeting and makes a case for the expansion of one of these measures. The methodology followed in designing questionnaires for use in initial pilot studies aimed at testing the usefulness of implementing such an expansion and the hypotheses tested in the studies are discussed in section four. The completed questionnaires are discussed in section five, and section six contains a statistical evaluation of results obtained from the questionnaires. Section seven provides conclusions and recommendations. 


\section{GENERAL SUPPORT MEASURES FOR AN INFLATION TARGET}

The advantages of an inflation target, set by government (see for instance South Africa, 2000) for its central bank to achieve through timely adjustments in monetary policy, have received considerable public attention (see for instance Casteleijn, 2001; De Wet, 2003; Du Plessis, 2003). In South Africa's instance the target is specified in terms of changes in CPIX, defined as changes in the consumer price index (CPI) for metropolitan and other urban areas excluding the interest cost of mortgage bonds (Mboweni, 2005). The main difference between CPI and CPIX is the exclusion of changes in the interest cost of mortgage bonds, which have a weight of 10,32 per cent in the overall CPI (Statistics SA, 2001). It is noteworthy that this exclusion is aimed at limiting the immediate effect of interest rate changes on the inflation figure used for targeting purposes, but that all changes in interest costs are not excluded. Changes in interest costs (of loans other than mortgage bonds) and bank charges account for a weight of 1,05 per cent in the CPI (Statistics SA, 2001), although no clear split is provided. Ideally these components should be split and published separately by Statistics SA. Moreover, CPIX does not cover rural areas.

The most obvious advantage of an inflation target is the clear final objective of monetary policy, i.e. price stability, which is "... readily understood by the public and thus highly transparent" (Mishkin, 2004:504). Moreover, "(i)nflation targeting is said to impose discipline on reserve banks, ... and foster the credibility of the reserve bank. This serves to anchor expectations of future inflation, and can help to resolve the time inconsistency problems associated with monetary policy" (Saunders, 2003:419). It is accordingly easy to judge the success or otherwise of the monetary authorities in achieving their goals, which improves accountability to the general public. Price stability as a goal also confirms the autonomy and independence of the central bank in selecting or adjusting policy instruments in its endeavours to achieve the target. As the policy framework is relatively easy to understand, it also enhances the transparency of policy decisions.

In inflation-targeting countries, there can be no ambiguity about the conduct of monetary policy. Without a clear single goal, a central bank can be entrusted seemingly conflicting goals to achieve. A case in point is the Federal Reserve System (Fed) in the United States of America, which has responsibility for more goals than only price stability, although it is argued that the Fed uses price stability to achieve its other goals. The general view is that the Fed, through the activities of the Federal Open Market Committee (its policy-setting body) has a "... so-called 'dual mandate' of fostering maximum employment as well as price stability" (Lacker, 2005). However, Lacker is of the view that these two goals are not mutually exclusive, as "... both experience and economic theory strongly suggest that the best contribution monetary policy can make to promoting employment and growth is by tying down inflation and inflation expectations. That is, in the long run, employment and growth are maximized by keeping inflation low and stable" (Lacker, 2005).

It is of interest, however, to note that the Fed has responsibility beyond the achievement of maximum employment and price stability. Lacker points out that "(i)f you go back and look at the direction Congress gave us - it appears in Section 2A of the Federal Reserve Act and was most recently revised in 1977 - you find that they actually gave us three mandates: 'maximum employment, stable prices, and moderate long-term 
interest rates'. Nobody ${ }^{1}$ mentions the third mandate, moderate long-term interest rates, and for good reason. It is widely understood that the best contribution monetary policy can make to keeping long-term interest rates low is by keeping expected inflation low, because this minimizes the inflation premium built into nominal long-term rates" (Lacker, 2005). Stable prices therefore foster maximum employment and interest rate moderation.

Owing to the forward-looking nature of an inflation-targeting regime, central banks in inflation-targeting countries have generally adopted three important support measures for their policy frameworks (Rossouw, 2005:295): inflation forecasting, explanation or escape clauses, and measuring inflationary expectations (opinion polls on inflation).

The first two of these support measures are broadly within the sphere of control of the central bank and/or the government. Under an inflation targeting policy regime, the central bank has the operational independence to employ the necessary human and other resources to develop and maintain forecasting capacity. The explanation or escape clause and its use are subject to agreement between the government, responsible for setting the inflation target, and the central bank with responsibility for achieving the target and for explaining any deviations from the target (Woglom, 2003:401), and is therefore also within their sphere of control.

South Africa uses an explanation clause in support of its inflation target. If the target is not achieved, the Reserve Bank has to explain to Parliament the reasons why it is not achieved and the measures instituted to ensure its achievement within a reasonable time.

New Zealand serves as a case in point in respect of the use of an escape clause measure. The Minister of Finance and the Governor of the central bank have to agree on and publish a Policy Target Agreement (PTA), which sets out specific inflation targets (Reserve Bank of New Zealand, 2004). However, "... the (New Zealand) Government has the power to override the PTA ... by directing the Reserve Bank to use monetary policy for a different economic objective (i.e. other than the achievement of price stability) altogether for a 12 month period, although it must make the instruction public" (Reserve Bank of New Zealand, 2004). This option has not been exercised to date by the New Zealand government.

The third measure (inflation expectations) is not within the immediate sphere of control of the authorities (Mishkin, 2004:419), although they can monitor inflation expectations. Inflation expectations are informed over time by the policy actions of the authorities and are measured by means of inflation opinion surveys. Bryan and Venkatu (2001) states that "...if economists hope to understand the behaviour of the marketplace, we must see through nominal values to the real returns on which monetary decisions are actually made". The most obvious way of sampling inflation expectations is by means of opinion polls; an approach that has been followed in South Africa since 1999 (Kershoff and Smit, 2002).

Inflation expectations are formed by and large through the historic policy decisions of central banks and their success in containing inflation, rather than through public announcements of the future intentions of the central bank. According to Mishkin,

\footnotetext{
${ }^{1}$ According to Lacker (2005) nobody makes mention of the third mandate, but this might be too strong a statement.
} 
$"$ "... an essential ingredient to a successful anti-inflation policy is the credibility of the policy in the eyes of the public ..." (2004:658). Central banks use inflation expectation surveys mainly " ... to (1) forecast inflation and (2) evaluate the credibility of their inflation fighting policies" (Kershoff and Smit, 2002:445,446). However, inflation expectation surveys tend to focus on the first, rather than the second, objective.

One approach to achieve the objective of policy credibility could be to make the central bank "... more independent from government and to charge it with the single responsibility of achieving and maintaining the price level" (Parkin, 1999:809; see also Mishkin, 2004:352354). De Wet (2003:799) confirms the view that "... the more independent the central bank is, the lower the inflation rate will be", citing a number of studies that had all found that "... independence and inflation are highly negatively correlated". The preference for an inflation objective entrusted to an independent central bank, overriding any discretion in policy decisions, is highlighted in the next section.

\section{PREFERENCE FOR AN INFLATION OBJECTIVE OVER MONETARY POLICY DISCRETION}

An example of time inconsistency in respect of a central bank's declaration that it will be tough on inflation in future, can be used to assess a preference for either an inflation objective or monetary policy discretion. However, if this central bank decreases the lending rate to commercial banks and thus relaxes monetary policy owing to job losses or complaints about tough business conditions at a time of rising inflation, the bank gives conflicting policy signals, leading to a general lack of credibility and hence expectations of possible future higher inflation.

For a better explanation of the trade-off between output and inflation, the Lucas supply curve could be considered. It is essentially the same as the expectations-augmented Phillips curve, with core inflation replaced by expected inflation (Romer, 2001:272). In this model, output (y) is modeled as a function of the full-employment level of output together with a weighted value of the difference between actual inflation and expected inflation (inflation gap):

$y_{t}=y_{f t}+a\left(\Pi_{t}-\Pi_{t-1}^{*}\right)$

where $y_{t}$ is output, $y_{f t}$ is full employment output, $\prod_{t}$ is the inflation rate and $\prod_{t-1}^{*}$ is

expectations at $\mathrm{t}-1$ of the inflation rate at $\mathrm{t}$.

On the other hand the central bank's preference function, with utility being a function of actual output and inflation, can be written as:

$$
z_{t}=y_{t}-b \prod_{t}^{2}
$$

where $z_{t}$ is the utility of the central bank.

This implies that the central bank's utility can be increased by either increasing output $\left(y_{t}\right)$, or decreasing inflation $\left(\Pi_{t}^{2}\right)$. In considering the two equations, there clearly exists an inherit tension for the central bank with regard to monetary policy implementation. For example, accelerating inflation will cause actual inflation to be higher than expected inflation and thus increase output over the short run. However, owing to the negative relationship of inflation and utility, the central bank's utility might 
decrease at the same time.

This leads to the rule versus discretion debate in the implementation of monetary policy. This debate stems from the claim that policy will be dynamically consistent if determined by rules. A central bank (or government) without monetary policy discretion may, under rational expectations, be expected to make short-run optimal decisions every time it can. It therefore has nothing to gain from its opportunism, producing on average better outcomes than a central bank with monetary policy discretion or a government with the ability to abandon temporarily its inflation target, as will be the case in New Zealand if its government ever elects to abandon temporarily the PTA (Fischer, 1990:1170; Reserve Bank of New Zealand, 2004; Mishkin, 2004:488).

If the central bank is bound by a framework or singular goal (e.g. an inflation target of between 3 and 6 percent in the case of South Africa), everybody is expected to know this framework and no change in output is thus expected as a result of a change in inflation. From the central bank's utility function it is concluded that the inflation rate preferred by the central bank will be equal to zero (or as close to zero as possible) or within the target range in a policy framework of inflation targeting, to make sure that no utility is lost. When the central bank is left to act upon its own discretion rather than entrusted with a singular goal, the resultant game theory (and particularly non-zero-sum games), based on the theory developed by John Nash (Parkin, 1999:296; Shubik, 1955:310), between the central bank and private economic agents, shows that the two players would permanently be trying to outsmart each other with respect to what inflation levels will be in the future.

To estimate actual inflation levels under discretion, it is necessary to consider simultaneously the Lucas supply curve and the preference function of the central bank.

This implies that the central bank aims at maximising its utility, $z_{t}=y_{t}-b \prod_{t}^{2}$, subject

to the Lucas supply curve $y_{t}=y_{f t}+a\left(\prod_{t}-\prod_{t-1}^{*}\right)$.

Thus by substituting $y_{t}$ :

$z_{t}=y_{f t}+a\left(\Pi_{t}-\Pi_{t-1}^{*}\right)-b \prod_{t}^{2}$

From here the first order conditions (FOC):

$\frac{\sigma Z_{t}}{\sigma \prod_{t}}=a-2 b \prod_{t}=0$

thus $\Pi_{t}=\frac{a}{2 b}$, with

$a$ being marginal benefit (MB) and $b$ marginal cost (MC).

This means that if the benefit of creating inflation is high, inflation will be high and to the contrary, if the cost of creating inflation is high, inflation will be low. In South Africa's case, the marginal cost of inflation is higher than the marginal benefit, meaning

$b$ will be higher and the Reserve Bank will therefore prefer inflation to be lower.

Kydland and Prescott (1977) observe that if expected inflation is low, so that the marginal cost of additional inflation is low, policymakers will pursue expansionary policies to push output temporarily above its normal level. However, if the public has knowledge that policymakers have this incentive, low inflation will in fact not be expected (De Wet, 2003:796). The end result is that policymakers' ability to pursue 
discretionary policy results in inflation without any increase in output (Romer, 2001:479). Depending on the actions of the central bank and the expectations of private economic agents, the possible outcomes to game theory highlighted below in Table 1 can evolve.

Table 1. Game theory

\begin{tabular}{|c|c|c|c|}
\hline & & Private economic agents & Private economic agents \\
\hline & & $\prod_{t-1}^{*}=0$ & $\prod_{t-1}^{*}=\frac{a}{2 b}$ \\
\hline Central bank & $\Pi_{t}=0$ & $\begin{array}{l}y_{t}=y_{f t} \\
\left(\text { good; no } \Delta \text { in } y_{t}\right)\end{array}$ & $\begin{array}{l}y_{t}<y_{f t} \\
\text { (can lead to recession) }\end{array}$ \\
\hline Central bank & $\Pi_{t}=\frac{a}{2 b}$ & $\begin{array}{l}y_{t}>y_{f t} \\
\text { (promotes } \uparrow \text { inflation) }\end{array}$ & $y_{t}=y_{f t}$ \\
\hline
\end{tabular}

Sourre: Based on De Wet, 2003; Mishkin, 2004

This Table highlights the actions of the central bank in the rows, and the actions of private economic agents in the columns. If the central bank has discretion to select a target and announces that its target inflation will be zero $\left(\Pi_{t}=0\right)$, the level of inflation $\left(\prod_{t-1}^{*}\right)$ that private economic agents will expect, depends on whether the announcement is credible or not. Private economic agents will, however, probably doubt the announcement because they know that under discretion the central bank will usually set a higher than zero target. Thus private economic agents will set their

expectations higher than zero $\left(\Pi_{t-1}^{*}=\frac{a}{2 b}\right)$.

From this the following will occur:

$$
\begin{aligned}
& y_{t}=y_{f t}+a\left(\prod_{t}-\prod_{t-1}^{*}\right) \\
& \text { with } \prod_{t}=0 \text { and } \prod_{t-1}^{*}=\frac{a}{2 b}, \\
& \therefore y_{t}=y_{f t}+a\left(0-\frac{a}{2 b}\right) \\
& \therefore y_{t}=y_{f t}-\frac{a^{2}}{2 b} \\
& \therefore y_{t} \downarrow
\end{aligned}
$$

which is likely to lead to a drop in output, and growth lower than potential growth, or even a recession in the economy.

This situation can be avoided by scrapping discretionary policy and forcing the central bank to use a monetary policy rule, e.g. an inflation target, which will ensure an optimal situation if the target is realistically achievable. A rule over discretion is preferred by Mishkin, who states that "... the Fed's policy regime ... might best be described as a 'just do it' policy ... (which) ... does not have a nominal anchor and is 
much less transparent ..." (2004:510).

The advantages of a rule over discretion were also emphasised in recent public addresses by the Presidents of two of the Federal Reserve Banks in the United States of America. Santomero (2005) is of the opinion that:

"(increasing the degree of central bank transparency is one reason I and some of my colleagues have spoken in favor of an explicit inflation-targeting program. I believe we have reached a point where institutionalizing inflation targeting simply makes good sense from an economic perspective. In short, it is a reasonable next step in the evolution of U.S. monetary policy, and it would help secure full and lasting benefits from our current stable price environment. Evolving to explicit inflation targeting from our current implicit target has significant potential benefits, and the costs may be minimal if we can implement it in a constructive manner. Clearly, proper implementation of inflation targeting is crucial to its success".

Uacker (2005) states that:

"... the Federal Reserve has made low inflation and the stabilization of inflation expectations a priority as never before in our history. My reading of the recent monetary history ... leads me to favor the adoption of an inflation target".

He points out three benefits of an explicit price-stability objective cited by the Federal Open Market Committee:

"(1) its usefulness as an anchor for long-term inflation expectations, (2) its power to enhance the clarity of Committee deliberations, and (3) its usefulness as a communication tool" and supports each of the three stated benefits (Uacker, 2005).

A move away from discretion towards an explicit target and single policy goal is therefore under consideration in the United States, despite the view that the Fed has already achieved "... credibility for low inflation ..." (Uacker, 2005).

It is, however, important to note that central banks using inflation targets measure their performance against the actual inflation rate, but do not measure whether the general public believes and generally accepts the published inflation figures as an accurate reflection of price rises in the economy. Any distrust of the published rate will be reflected in inflation expectations in the long run, hence not supporting the notion that "(i)nflation would be eliminated at once with no loss of output if the policy is credible" (Mishkin, 2004:673). The credibility of inflation figures is highlighted in the next section of this paper.

\section{THE CREDIBILITY OF INFLATION FIGURES}

Generally the public finds it difficult to understand how inflation is measured and has difficulty understanding the true meaning of what is measured, i.e. average increases in prices over a specific period for an average household. In addition, "... the accuracy of the ... official inflation rate is also frequently doubted, due to the consumer's experience of much higher general price increases whilst purchasing groceries" (Du Toit, 1988).

Indices used for the measurement of price changes are often questioned on the basis that they do not reflect sufficiently the spending pattern of an average household owing to substitution of either products and services consumed, or outlets where goods and services are purchased. This problem could in part be overcome by regularly updating the "basket" used for measuring inflation in terms of new consumer goods and improved services, quality changes and substitution of outlets (Parkin, 1999). These 
misconceptions cast doubt in the public mind on the published inflation statistics, and therefore over the actual successes or otherwise of the central bank in achieving the inflation target.

This occurred in Japan, where official statistics reported an average annual increase of 1,4 per cent in inflation during the ten-year period after 1985, whereafter the Japanese economy moved into a prolonged period of deflation. However, the inflation figures published prior to deflation was often criticised. "Some economists and journalists criticised ... the CPI ... (as not reflecting) ... the real changes of the price level. They believed that the CPI overstated the price increase rate..." (Statistics Bureau, 1993:3).

As stated above, central banks should use inflation expectation surveys, inter alia, to "... evaluate the credibility of their inflation fighting policies" (Kershoff and Smit, 2002:445,446), but this objective and the measurement of the public's acceptance (or otherwise) of inflation figures achieved by inflation targeting policies have received little attention from central banks or in the literature on the implementation of inflation targeting. Should the public not accept the data, a policy of inflation targeting could hardly be followed in a country that have historically suffered persistently high inflation, as the public (i.e. private economic agents) would act according to perception, i.e. as if inflation remains high. In terms of Table 1, such action will induce a decline in real

output $\left(y_{t} \downarrow\right)$. Even if the target is achieved, the public will simply not accept that

monetary policy has been successful, implying that inflation expectations will not be moderated as the policy will lack credibility. The further challenge is therefore to measure not only inflation expectations, but to measure also the public's general acceptance of official inflation statistics by means of opinion polls, which would assist in estimating future inflation expectations. Guarding against any increases in inflation expectations is in the interest of central banks. Lacker (2005) states that "... low and stable inflation expectations have enhanced the ability of monetary policy to react flexibly to both positive and negative shocks ... ". The measurement of any decline in the general acceptance of published inflation figures will serve as an early warning for a possible change in inflation expectations, as " ... a central bank ... does not have control over expectations of inflation" (Mishkin, 2004:419).

To this end, the measurement of the degree of acceptance (or otherwise) of the inflation figures as an accurate indication of inflation by means of an opinion poll aimed at the compilation of an inflation credibility barometer (i.e. a degree of acceptance of inflation figures as an accurate indication of price increases) was suggested before (Rossouw, 2003:84). Moreover, the compilation of a questionnaire to be used for this purpose was also suggested, but it has not yet been put to the test. In the next section the design of questionnaires for use in pilot studies aimed at measuring the credibility of inflation is highlighted.

\section{MEASUREMENT OF INFLATION CREDIBILILY: QUESLIONNAIRE DESIGN, REUSE AND REDESIGN}

Based on the earlier proposals for the content of a questionnaire to use for the compilation of an inflation credibility barometer (Rossouw, 2003:84), a first questionnaire, attached as Annexure A, was developed for use in a first pilot study aimed at measuring inflation credibility. Three groups of respondents were selected to complete the 
questionnaire. For control purposes and to prevent a situation where one respondent could complete more than one questionnaire, respondents were requested in all instances to identify themselves in the completed questionnaire.

Question one of the questionnaire provides the most recent official inflation figure at the time to respondents. Kershoff and Smit (2002) states that

"(t)he benefit of providing historical information is that all respondents have the same information available when completing the questionnaire ... (as) ... historic information provides respondents with a benchmark".

Respondents were requested to indicate whether this figure is a true reflection of average price increases.

Question two provided in section (a) an option of stating that inflation was lower than published to cater for such perceptions. In the alternatives in question 2(b), dealing with a perception that inflation was higher than published, three possible alternatives that would not contribute to increases in the price level (e.g. expensive food) were deliberately included.

The questionnaire was completed by three groups of respondents with the aim of testing three hypotheses, namely whether: (i) the questionnaire is suitable for broader use; (it) respondents generally accept inflation figures as accurate; and (Hi) respondents have a clear understanding of the meaning and measurement of inflation.

Owing to unsatisfactory survey results obtained from the first pilot studies, two different second pilot studies were conducted, using the same groups of respondents, to test a fourth hypothesis that knowledge and information improve the credibility of inflation data. In one instance the respondents were requested to complete the first questionnaire for a second time. In the second instance a shortened second questionnaire, highlighted in Annexure B, was developed for completion by the two other groups of respondents. It comprises one question only, pertaining to the accuracy of the rate of inflation used for targeting purposes, rather than the overall rate of inflation.

The completed questionnaires are assessed in the next section.

\section{COMPLETION OF QUESTIONNAIRES AND SURVEY RESULTS}

The first questionnaire was completed under supervision as a first phase of the first pilot study by 20 MBA preparatory students at the University of Pretoria. This group was selected as a first sample owing to the small number of students.

As students completing the first questionnaire experienced no difficulties, two larger groups of second-year students following the EKN 213 and EKN 215 courses, respectively, at the same University subsequently completed it as a second phase of the first pilot study. As the courses followed by both these groups of students have banking studies and monetary policy as their main aims, they were selected on the basis that all of the first three hypotheses could be tested.

The response of the MBA preparatory students is highlighted in Annexure C. As only one student accepted the inflation figure as accurate, the credibility barometer reads 5 (out of a possible 100), as is shown in Fig. 1.

The responses of two groups of second year students in the first pilot study are 
highlighted in Annexures D and E, respectively. The sample comprised 11 EKN 213 and 90 EKN 215 students. It was somewhat disconcerting that the analysis of the results obtained from the EKN 213 and EKN 215 students showed that an inflation credibility barometer could hardly be constructed by expressing the total number of "yes" responses to question 1 as a percentage of the total responses, owing to a low degree of acceptance of the official inflation figure as a true reflection of average price increases, as is also highlighted in Fig. 1 below.

In respect of the EKN 213 students, the credibility barometer reads 18 (out of a possible 100), as two out of 11 students accepted the inflation figure as accurate. Only one student mentioned a perception of price increases lower than the inflation figures.

It is important to note that three students (some 27 per cent), mentioned as reasons for a perception of higher inflation an item (high prices) that is not used for measuring the rate of inflation. The sample therefore did not support the first three hypotheses, casting doubt on people's understanding of the meaning of inflation figures.

Broadly similar results were obtained from the questionnaires completed by the EKN 215 students. In this case the credibility barometer reads 13 (out of a possible 100) as 12 out of 90 students accepted the inflation figure as accurate, as is highlighted in Fig. 1 below. Some 6 per cent of students indicated that price increases were lower than the inflation figures.

In addition, 17 students (i.e. some 19 per cent) mentioned as reasons for a perception of higher inflation one of the items that are not used for measuring the rate of inflation. The first three hypotheses were again not confirmed, raising the challenge of formulating and testing the fourth hypothesis (knowledge and information improve inflation credibility) by means of a second pilot study.

As the group of 20 MBA preparatory students had no previous formal post-school training in economics and in view of the unsatisfactory findings about the acceptance of inflation figures, it was decided to do a second pilot study with this group. They were requested to complete the first questionnaire for a second time after an extensive lecture on the measurement of inflation, inflation targeting as a monetary policy framework and the use of inflation targets in South Africa. A comparison of the results of their first and second pilot studies, highlighted in Annexure C, confirmed the fourth hypothesis: knowledge and information increase the credibility of inflation figures. The credibility barometer reads 45 in the second study, indicating a much higher degree of acceptance of the inflation figure as an accurate indication of inflation after the lecture on inflation, as is shown in Fig. 1.

Three respondents in the second sample still mentioned as reasons for a perception of inflation at a level higher than the official rate items not used for measuring the rate of inflation. This casts some doubt on the ability of people to understand fully in a reasonably short period of time the meaning of inflation figures. To the extent to which this group of students reflects a cross-section of the general public, prolonged communication would be required to increase the public's general level of understanding inflation.

In an attempt to find an answer to a further question whether the general use of too many different inflation figures in the media, e.g. changes in the CPI, CPIX or PPI, could be confusing, a shortened second questionnaire was compiled for completion in a second pilot study by the same two second-year student groups. However, the second questionnaire stated the inflation figure used for targeting purposes, rather than the 
overall inflation figure. The results of the second pilot study are also summarised in Annexures D and E, respectively. The sample comprised 16 students registered for EKN 213 and 62 registered for EKN 215. It was decided not to have the second questionnaire completed by the MBA students to prevent "sampling fatigue", as they were requested to complete twice the first questionnaire used for the first pilot study.

In the second sample of EKN 213 students, the credibility barometer reads 81 (out of a possible 100) as 13 out of 16 respondents accepted the inflation figure used for targeting purposes as accurate, as can be seen from Fig. 1. In respect of the EKN 215 students, the credibility barometer reads 63 (out of a possible 100) as 39 out of 62 respondents accepted the inflation figure as accurate, as can also be seen from Fig. 1. In both cases a marked improvement in the reading of the barometer was recorded.

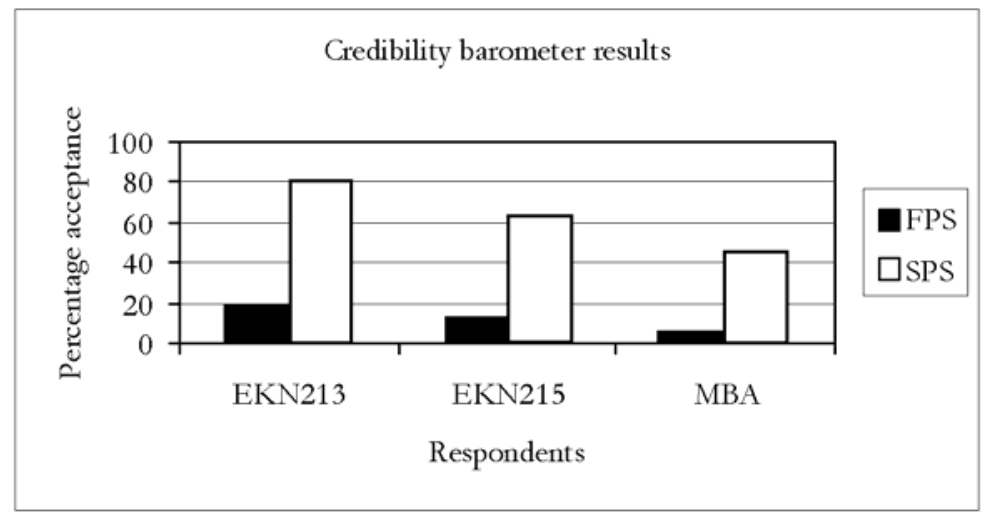

Figure 1.The inflation credibility barometer: summary results of the first two pilot studies FPS: First pilot study SPS: Second pilot study

A statistical evaluation of results obtained from the questionnaires is highlighted in the next section.

\section{STATISTICAL EVALUATION OF THE RESULTS OBTAINED FROM THE QUESTIONNAIRES}

The above results were evaluated statistically using the Statistical Analysis System (SAS), owing to the fact that the research has a binary outcome variable for the dependent variable, as the response can either be YES or NO. The aim of the analysis is not to obtain a specific value for the dependent variable, but rather in estimating the probability of obtaining YES or $N O$ for a specific question.

The specific method used was the calculation of a two-way frequency Table using the Proc Frequency (PROC FREQ) procedure. Frequency Tables show the distribution of variable values. Cross-tabulation Tables show combined frequency distributions for two or more variables. For two-way Tables, as in this case, PROC FREQ computes tests and measures of association. PROC FREQ can use either raw data or cell count data to produce frequency and cross-tabulation Tables. Raw data, also known as case-record data, report the data as one record for each subject or sample member (SAS, 1999-2001 help files).

The data for each group individually and as a group were evaluated by expressing the total of each 'yes' and 'no' answers in both of the studies. The following Tables 
summarise the results obtained.

Table 2. Probability of obtaining a Yes' answer

\begin{tabular}{lll}
\hline GROUP & FPS & SPS \\
EKN213 & 18.18 & 81.25 \\
EKN215 & 13.33 & 62.96 \\
MBA & 5.00 & 45.00 \\
TOTAL & 12.40 & 62.24 \\
\hline
\end{tabular}

Table 3. Probability of obtaining a 'No' answer

\begin{tabular}{lll}
\hline GROUP & FPS & SPS \\
EKN213 & 81.82 & 18.75 \\
EKN215 & 86.67 & 36.16 \\
MBA & 95.00 & 55.00 \\
TOTAL & 87.60 & 37.76
\end{tabular}

Note: The results represent the probabilities, which were calculated by SAS from the obtained odds ratio

From both the above output tables (which is basically an inverse of each other) there is a clear statistically different outcome between results form the first pilot study and those of the second pilot study. This general trend in the data holds for each group individually as well as for the total of the groups put together as can be seen from Table 4 .

Table 4. Results of the Proc Freq procedure: summary of the total pilot studies

\begin{tabular}{|c|c|c|c|c|}
\hline \multirow{4}{*}{\begin{tabular}{|l} 
Frequency \\
Per cent \\
Row Pct \\
Col Pct
\end{tabular}} & \multicolumn{4}{|c|}{ Table of Defaults by Study } \\
\hline & \multirow[b]{2}{*}{ Defaults } & \multicolumn{2}{|c|}{ Study } & \multirow[b]{2}{*}{ Total } \\
\hline & & FPS & SPS & \\
\hline & \multirow[t]{3}{*}{ no } & 106 & 37 & \multirow{3}{*}{$\begin{array}{c}143 \\
65.30\end{array}$} \\
\hline & & $\begin{array}{l}48.40 \\
74.13\end{array}$ & $\begin{array}{l}10.89 \\
25.87\end{array}$ & \\
\hline & & 87.60 & 37.76 & \\
\hline & \multirow[t]{4}{*}{ yes } & 15 & 61 & \multirow{4}{*}{$\begin{array}{c}76 \\
34.70\end{array}$} \\
\hline & & 6.85 & 27.85 & \\
\hline & & 19.74 & 80.26 & \\
\hline & & 12.40 & 62.24 & \\
\hline & \multirow[t]{2}{*}{ Total } & 121 & 98 & 219 \\
\hline & & 55.25 & 44.75 & 100.00 \\
\hline
\end{tabular}

The outcomes of the two studies are compared by assessing the total percentages. The probability of a YES response in the first pilot study is 6,85 per cent compared to the probability of 27,85 per cent for a YES response in the second pilot study. This confirms that the credibility of the inflation figure increased after more information regarding inflation and its calculation was disseminated.

The conclusions and recommendations from these first attempts at measuring inflation credibility follow below.

\section{CONCLUSIONS AND RECOMMENDATIONS}

The general conclusions from the first attempts at measuring inflation credibility and constructing an inflation credibility barometer are summarised below by means of four conclusions and three recommendations.

The first conclusion is that the first hypothesis (confirmation of the general usefulness of the first questionnaire) is not confirmed: the level of acceptance of the 
overall rate of inflation as an accurate indication of inflation was so low that an inflation credibility barometer could hardly be constructed.

Secondly, in their completion of the questionnaire in the first pilot study, all three groups of students have recorded a very low level of acceptance of the overall inflation figure. The second hypothesis (general acceptance of the overall inflation) was therefore not confirmed. Moreover, respondents had no general perception that inflation was lower than the published figure.

Thirdly, the two groups of second year students have shown broadly the same insight into the measurement of inflation as the MBA preparatory students, used as proxy for the general public. Inflation and its measurement are indeed not well understood, even by economics students, and the third hypothesis was therefore not confirmed.

Fourthly, the second pilot studies recorded a higher degree of credibility of inflation figures. This result confirms the fourth hypothesis about a level of knowledge and understanding about inflation increasing the credibility of inflation figures, hence contributing to containing inflation expectations:

(i) The dissemination of information (i.e. a lecture on inflation before a survey sample) increases the credibility of published inflation data, confirming the need for knowledge and information. The questionnaires provide insight into possible future inflation expectations - if the rate of inflation is accepted as an accurate indication of price increases, people would base their future inflation expectations on this perception. (it) The abridged format used in the second questionnaire, completed by the two groups of second-year students, resulted in achieving the highest degree of acceptance of the stated inflation data as a true measure of price increases. As the use of a single question increased the credibility of the inflation figure, the inclusion of subsequent questions could "induce" respondents to respond negatively to the question on the credibility of inflation.

(Hi) In the second questionnaire, stating the change in the CPIX, a much higher level of general acceptance of the inflation figure was recorded. As this is the rate of inflation used for inflation targeting purposes and therefore the rate receiving extensive media coverage, the conclusion is that media coverage increases the credibility of inflation figures and therefore helps to anchor inflation expectations.

The first recommendation is that communication should be improved about one specific measure of inflation. The inflation figure used for inflation targeting in a country following such a policy would be the preferred measure. However, this conclusion could be tested in a next pilot study by splitting the respondents into two groups and putting one question only to each group: the overall rate of inflation in one instance and the rate used for inflation targeting in the second instance.

The second recommendation is that questionnaires aimed at measuring inflation credibility for constructing an inflation credibility barometer should be based on the abridged format used in the second questionnaire, as this format delivered satisfactory results.

The remaining question for debate in the case of South Africa is whether the use of CPIX for purposes of inflation targeting is appropriate in view of the challenge to enhance the communication required to inform the general public about the true meaning and measurement of inflation, aimed at anchoring inflation expectations. The third recommendation is that an alternative, i.e. CPIXX (definable as changes in the 
consumer price index excluding interest costs), rather than CPIX, be considered for use as an inflation target specification, owing to its less cumbersome definition, coverage of the whole country (i.e. inclusive of rural areas), and relative ease of communication.

Annexure A

QUESTIONNAIRE FOR USE TO ESTABLISH THE CREDIBILITY OF PUBLISHED OFFICIAL INFLATION FIGURES

Student group: .......... Name: ............... Student number:

Question 1: South Africa's official rate of inflation for 2004 was 1,4 per cent. Is this a true reflection of average price increases?

YES / NO

If your answer is "YES" to question 1, please ignore the rest of this questionnaire. If your answer is "NO" to question 1, please consider the alternatives in question 2.

Question 2 (please select only one):

(a) Actual price increases were lower than the inflation rate; or

(b) Actual price increases were higher than the inflation rate, as is clear from:

Increasing food prices

Higher oil prices

Increasing property prices

Expensive food

High prices

Too little money to spend

Thank you for your co-operation in the compilation of this questionnaire.

Annexure B

ADDITIONAL QUESTIONNAIRE FOR USE TO ESTABLISH THE CREDIBILITY OF PUBLISHED OFFICIAL INFLATION FIGURES USED FOR INFLATION TARGETING PURPOSES

Your co-operation in the compilation of this questionnaire will be appreciated

Student group: .......... Name: ............... Student number: ....

South Africa's official rate of inflation for inflation targeting purposes (CPIX) was 4,3 per cent in 2004. Is this a true reflection of average price increases?

YES / NO

Annexure C

ANALYSIS OF QUESTIONNAIRES USED TO ESTABLISH THE CREDIBILITY OF PUBLISHED OFFICIAL INFLATION FIGURES COMPLETED BY MBA PREPARATORY STUDENTS

Sample size:

Inflation for 2004 was measured accurately

Actual inflation for 2004 was lower than reported

Actual inflation for 2004 was higher than reported as is clear from:

(i) Increasing food prices

(ii) Higher oil prices

(iii) Increasing property prices

(iv) Expensive food

(v) High prices

(vi) Too little money to spend

No clear indication

$\begin{array}{cc}\text { FPS }^{1} & \text { SPS }^{2} \\ 20 & 20 \\ 1 & 9 \\ 2 & 1 \\ & \\ 5 & 2 \\ 3 & 1 \\ 5 & 1 \\ - & 1 \\ 2 & 2 \\ 1 & - \\ 1 & 3\end{array}$

1 First pilot study: before a lecture on inflation

2 Second pilot study: after a lecture on inflation 


\section{Annexure D}

ANALYSIS OF QUESTIONNAIRES USED TO ESTABLISH THE CREDIBILITY OF PUBLISHED OFFICIAL INFLATION FIGURES COMPLETED BY EKN 213 STUDENTS

Sample size:

FPS1 SPS $^{2}$

Inflation for 2004 was measured accurately

$11 \quad 16$

Actual inflation for 2004 was lower than reported

213

Actual inflation for 2004 was higher than reported as is clear from:

(i) Increasing food prices

(ii) Higher oil prices

(iii) Increasing property prices

$1 \mathrm{n} / \mathrm{a}$

(iv) Expensive food

(v) High prices

(vi) Too little money to spend

$\begin{array}{ll}2 & \mathrm{n} / \mathrm{a} \\ 2 & \mathrm{n} / \mathrm{a} \\ 1 & \mathrm{n} / \mathrm{a} \\ - & \mathrm{n} / \mathrm{a} \\ 3 & \mathrm{n} / \mathrm{a} \\ - & \mathrm{n} / \mathrm{a}\end{array}$

Annexure E

ANALYSIS OF QUESTIONNAIRES USED TO ESTABLISH THE CREDIBILITY OF PUBLISHED OFFICIAL INFLATION FIGURES COMPLETED BY EKN 215 STUDENTS

Sample size:

Inflation for 2004 was measured accurately

Actual inflation for 2004 was lower than reported

$\mathrm{FPS}^{3} \quad \mathrm{SPS}^{4}$

Actual inflation for 2004 was higher than reported as is clear from:

(i) Increasing food prices

(ii) Higher oil prices

(iii) Increasing property prices

(iv) Expensive food

(v) High prices

(vi) Too little money to spend

$\begin{array}{rc}90 & 62 \\ 12 & 39 \\ 5 & \text { n/a }\end{array}$

$\begin{array}{rl}10 & \mathrm{n} / \mathrm{a} \\ 22 & \mathrm{n} / \mathrm{a} \\ 24 & \mathrm{n} / \mathrm{a} \\ 2 & \mathrm{n} / \mathrm{a} \\ 12 & \mathrm{n} / \mathrm{a} \\ 3 & \mathrm{n} / \mathrm{a}\end{array}$

\section{REFERENCES}

BRYAN, MF. and VENTAKU, G. (2001). The demographics of inflation opinion surveys. Economic Commentary. Federal Reserve Bank of Cleveland. 15 October.

CASTELEIJN, A. (2001). South Africa's monetary policy framework. Paper prepared for the Conference on monetary policy frameworks in Africa, 17 to 19 September. SA Reserve Bank, Pretoria.

DE WET, WA. (2003). Thinking like a Governor: Central banking under an inflation target. The South African Journal of Economics. Vol 71:4. December.

Du PLESSIS, SA. (2003). Much ado about nothing: a note on the modified inflation target. The South African Journal of Economics. Vol 71:2. June.

DU TOIT, APT. (1988). Some misconceptions surrounding the consumer price index and the producer price index. The Securities Markets. Number 10, Fourth Quarter.

FISCHER, S. (1990). Rules versus Discretion in Monetary Policy. Chapter 21 in Friedman, BM. and Hahn, FH. Handbook of Monetary Economics. Vol. II. The Netherlands: Elsevier, Amsterdam.

KERSHOFF, GJ. and SMIT, BW. (2002). Conducting inflation expectation surveys in South Africa. The South African JournaI of Economics. Vol 70:3. March.

KYDLAND, FE. andPRESCOTT, EC. (1977). Rules rather than discretion: The time inconsistency of optimal plans. Journal of Political Economy. Vol 85:3. June.

LACKER, JM. (2005). Inflation Targeting and the Conduct of Monetary Policy. Remarks by the President of the Federal Reserve Bank of Richmond at the University of Richmond, Virginia. [Online]. http://www.nch.frb.org/media/speeches/index.cfm/id=70 [Accessed 7 March 2005].

${ }^{1}$ First pilot study: first questionnaire

2 Second pilot study: second questionnaire

${ }^{3}$ First pilot study: first questionnaire

${ }^{4}$ Second pilot study: second questionnaire 
MBOWENI, TT. (2005). Statement of the Monetary Policy Committee. SA Reserve Bank. 10 February. [Online]. http://www.reservebank.co.za/ [Accessed 28 February 2005].

MISHKIN, FS. (2004). The Economics of Money, Banking and Financial Markets. $7^{\text {th }}$ ed. United States of America: AddisonWesley Publishing Company, Inc.

MOHR, P. and FOURIE, L. (eds). (2004). Economics for S'outh African students, $3^{\text {rd }}$ ed. Pretoria: Van Schaiks.

PARKIN, M. (1999). Economics. $5^{\text {th }}$ ed. United States of America: Addis on-Wesley Publishing Company, Inc.

RESERVE BANK OF NEW ZEALAND. (2004). What is the Policy Targets Agreement? [Online]. http//www.rbnz.govt.nz

[Accessed 3 August 2004].

ROMER, D. (2001). Advanced Macroeconomics. $2^{\text {nd }}$ ed. United States of America: McGraw Hill Irwm.

ROSSOUW, J. (2003). Building inflation credibility. Central Banking Vol XIII, No. 4. May. Central Banking Publications,

London.

(2005). Monetere beleid in Suid-Afnka sedert 1965: die vordenng vanaf direkte beheer tot mflasieteikens. Tydskrif

vir Geesteswetenskappe. Suid-Afnkaanse Akademie vir Wetenskap en Kuns. Jaargang 45:2. Junie 2005.

SANTOMERO, AM. (2005). Eessons Eearnedfrom the Recent Business Cycle. Address by the President of the Federal Reserve

Bank of Philadelphia at the American Academy in Berlin. 1 March.

[Online], http://www.phil.frb.org/publicaffairs/speeches/2005_santomero2.html [Accessed 7 March 2005].

SAUNDERS, S. (2003). The experience of inflation targeting in Australia: Lessons for South Africa. The South African

Journal of Economics. Vol 71:2. June.

SHUBIK, M. (1955). The uses of game theory in management science. Article reprinted in Mansfield, E. (1975).

Microeconomics: selected readings. $2^{\text {nd }}$ ed. United States of America: WW Norton and Company, Inc.

STATISTICAL ANALYSIS SYSTEM (SAS) FOR WINDOWS. $\quad$ (1999 - 2001). Version 8.2. United States of America: SAS Institute Inc.

STATISTICS BUREAU. (1996). Conflicts between innovation and continuity: Japan's case. Paper prepared for the United Nation's seminar on official statistics — past and future. 25 to 27 September. Lisbon, Portugal.

STASTISTICS SA. (2001). Consumer Price Index — detailed weights: historical metropolitan and other urban areas. P0141.5

SOUTH AFRICA. (2000). Budget speech by the Minister of Finance. 23 February.

WOGLOM, G. (2003). How has inflation targeting affected monetary policy in South Africa? The South African Journal of

Economics. Vol 71:2. June. 